\title{
Posición subjetiva y acto delictivo en condenados por homicidio y delito sexual*
}

DOI: https://doi.org/10.18046/recs.i3o.3107

\author{
Subjective Position and Criminal Act in Convicted \\ of Homicide and Sexual Offense
}

\author{
Ana Lucía Arango-Arias ${ }^{* *}$ \\ Universidad Católica de Pereira (Pereira, Colombia) \\ César Alberto Soto-Echavarría ${ }^{* *}$ \\ Universidad Católica de Pereira (Pereira, Colombia)
}

\begin{abstract}
* Este artículo presenta resultados de investigación empírica desde y con el psicoanálisis lacaniano, en el proyecto de investigación "La posición subjetiva frente al acto delictivo en la población con pena privativa de la libertad en el establecimiento penitenciario de mediana seguridad y carcelario de Pereira (EPMSCPEI)", por parte del grupo Clínica y Salud Mental, línea Psicoanálisis, Trauma y Síntomas Contemporáneos, de la Universidad Católica de Pereira (Colombia). El proyecto es financiado por la Universidad Católica de Pereira y se realiza en convenio con el Establecimiento Penitenciario de Mediana Seguridad y Carcelario de Pereira (EPMSC-ERE), INPEC. Artículo de investigación recibido el 09.08.2018 y aceptado el 16.10.2019.

** Investigadora principal. Magíster en Filosofía de la Universidad de Caldas (Colombia). Especialista en Psicología Clínica con Orientación Psicoanalítica de la Universidad San Buenaventura, Cali (Colombia). Psicóloga de la Universidad de Manizales (Colombia). Docente e investigadora en el programa de Psicología de la Universidad Católica de Pereira (Colombia), grupo Clínica y Salud Mental, línea Psicoanálisis, Trauma y Síntomas Contemporáneos. Correo electrónico: ana.arango@ucp.edu.co ORCID: http://orcid.org/oooo-ooo2-0634-9110

*** Coinvestigador. Magíster en Psicoanálisis de la Universidad Argentina John F. Kennedy (Argentina). Psicólogo de la Universidad Católica de Pereira (Colombia). Coordinador de la Especialización en Psicología Social Comunitaria y Acción Psicosocial de la Universidad Católica de Pereira (Colombia), docente en la Facultad de Ciencias Humanas, Sociales y de la Educación e investigador en el grupo Clínica y Salud Mental, línea Psicoanálisis, Trauma y Síntomas Contemporáneos. Correo electrónico: cesar.soto@ucp.edu.co ORCID: http://orcid.org/oooo-ooo2-5864-9238
\end{abstract}




\section{Cómo citar/How to cite}

Arango-Arias, Ana Lucía; Soto-Echavarría, César Alberto (2020). Posición subjetiva y acto delictivo en condenados por homicidio y delito sexual. Revista CS, 30, 229-249. https://doi.org/10.18046/recs.i30.3107 


\section{Resumen}

La investigación tuvo como objetivo relacionar la posición subjetiva y las categorías clínicas del acto, en personas que cometieron delitos y se encuentran privadas de la libertad. Se realizaron entrevistas de localización subjetiva a seis condenados por homicidio o por delito sexual con menores de 14 años. Cada entrevista es un texto por descifrar, localizando en el campo de la enunciación los significantes que insisten y que, al conectarse, desvelan algo de la singular posición del sujeto frente al acto delictivo. Para los resultados se elige un caso de homicidio que ejemplifica las categorías de análisis de la investigación, encontrándose la secuencia crimen-culpa-responsabilidad-significación de la pena, cadena lógica que permite pensar en una posición singular del sujeto ligada al discurso del Otro como ley. Se concluye que la lógica subjetiva (singular) vincula cinco puntos interconectados: significante, goce, cuerpo, fantasma y categorías clínicas del acto.

\section{PALABRAS CLAVE:}

posición subjetiva, acto delictivo, acting out, pasaje al acto, ley psíquica

The research aimed at relating the subjective position and the act's clinical categories in persons who committed criminal acts and are deprived of their liberty. Subjective interviews were conducted with six subjects convicted of homicide or sexual offense with minors under 14. Each interview was a text to be deciphered, the signifiers that insist and that, when connected, reveal something about the singular position of the subject in facing the criminal act needed to be traced during enunciation. For the results, a case of homicide that exemplifies the research's analysis categories is chosen. The sequence crime-guilt-responsibility-meaning of the sentence is found, which is a logical chain that allows to think of a singular position of the subject linked to the Other's discourse as law. It is concluded that the singular subjective logic links five interconnected points: signifier, jouissance, body, phantom, and act's clinical categories.

\section{KEYWORDS:}

Subjective Position, Criminal Act, Acting Out, Passage to the Act, Psychic Law 



\section{Introducción}

La presente investigación aborda la cuestión de las relaciones que pueden establecerse entre la posición subjetiva, el acto delictivo y las categorías clínicas del acto (acting out y pasaje al acto), desde la perspectiva del psicoanálisis lacaniano. Dicha relación se establece por la vía de la escucha del discurso de personas que han cometido actos delictivos y se encuentran, por ello, condenadas a la privación de la libertad.

Lo anterior impone que se toquen asuntos que implican la relación entre el derecho y el psicoanálisis, la cual no es novedosa y se ha caracterizado por encuentros y desencuentros en torno a cuestiones comunes a ambas disciplinas, como lo son la ley, la culpa, la responsabilidad y el castigo. No obstante, esta situación siempre da lugar a renovados intereses en los que se problematizan aspectos paradójicos de la realidad social, en este caso el acto delictivo, entendiendo que, si bien este es un fenómeno social, se encuentra enmarcado en el lazo social, y todo lazo social, como afirmó Lacan (2008), en el seminario “El reverso del psicoanálisis", está fundado en el lenguaje, y es, por tanto, discurso. De este último puede decirse que es "un orden impuesto a algo real" (Soler, 2015: 52), para que sean posibles los lazos sociales; de este modo, el derecho, en cuanto discurso del amo, se ocupa del delito; mientras que el psicoanálisis, del goce, aportando a la lectura algo real que está en juego allí, en tanto hay un sujeto cuyo goce transgrede y es "incompatible con el orden social y subjetivo" (Soler, 2015: 51).

De este modo, en el artículo se muestra la manera como estos dos discursos pueden articularse al problema del delito: el discurso del Otro que, con sus leyes, prescribe formas sociales de actuación o las proscribe como des-orden, siendo que su razón de ser y su función se subordinan a la instauración de la ley y a la reglamentación del campo del goce; y el psicoanálisis, que se ocupa de un sujeto en el que se moviliza un saber no sabido acerca del goce implicado en su acto y de la responsabilidad subjetiva que esto conlleva. El discurso del derecho penal concibe, respecto a la transgresión del sujeto, una responsabilidad jurídica que establece la correspondencia objetiva entre el tipo de delito cometido y la pena recibida, lo que deja al sujeto al margen de poder implicarse en su acto y trae, como efecto no deseable, la computación de las penas.

Ahora bien, si dentro de las funciones de la pena se contemplan la prevención especial y la reinserción social o resocialización (Congreso de Colombia, 2000), con las que se pretende que una persona que ha sido condenada no vuelva a delinquir y adquiera la capacidad de respetar la ley para convivir dentro del orden social, sería necesario contar con el asentimiento subjetivo de aquel que incurre en el acto delictivo, pues una pena impuesta a un delito, en la que el sujeto no reconoce lo que de su subjetividad está implicado, resulta inútil. 
Para el psicoanálisis lacaniano, el delito no es una conducta, sino un acto, esto es, un hecho de lenguaje, un discurso que se presta para ser descifrado, es por ello que Gerez-Ambertín (2006:47) plantea que "será tarea del psicoanálisis dar cuenta de cómo se subjetiviza lo prohibido y cuáles son las causas que llevan a los hombres a precipitarse en ese cono de sombras de lo ilícito". Así, al asumir la responsabilidad subjetiva, el condenado también puede encontrar el sentido de la pena impuesta desde el discurso jurídico.

En este orden de ideas, la investigación se vale de un diseño metodológico apoyado en el dispositivo clínico preliminar del psicoanálisis, específicamente las entrevistas de localización subjetiva, para indagar, en seis personas condenadas por los delitos de homicidio y abuso sexual con menores de 14 años, su posición subjetiva frente al acto delictivo y la relación con las categorías clínicas del acto. Los objetivos del proyecto, mencionados a continuación, sirvieron como ejes procesuales para: localización de la posición subjetiva; ubicación de aquellos elementos del discurso como el enunciado y la enunciación, dando cuenta de la responsabilidad del sujeto frente a su acto y la significación que da a la sanción penal; $\mathrm{y}$, finalmente, de las relaciones entre la posición subjetiva localizada en cada uno de los condenados y las categorías clínicas psicoanalíticas del acting out y el pasaje al acto, todo esto teniendo en cuenta la singularidad, caso por caso.

Se encuentra que la posición subjetiva es un elemento primordial para dilucidar cómo los elementos estructurales que operan en el sujeto como el goce, deseo y fantasma ${ }^{1}$, se ordenan en relación con una lógica pulsional singular en aquel que comete un acto delictivo, y cómo estos, a su vez, permiten señalar la presencia de una o ambas categorías clínicas del acto en cada uno de los casos, pero, también, encontrar cuándo el delito no se relaciona con estas, sino que se constituye como síntoma en el sujeto. En concordancia con lo anterior, se señala la importancia que

1. Los conceptos aquí mencionados son propios del psicoanálisis lacaniano y pueden definirse a partir de los registros: simbólico, imaginario y real, con los que Lacan aborda la subjetividad. Si pensamos el inconsciente como estructurado por una cadena de significantes (campo simbólico), podemos entender que el sujeto del inconsciente es aquello que es representado en esta cadena. Lo imaginario es el campo de las identificaciones, de lo especular, está representado por la imagen que es introyectada del Otro como semejante y que da consistencia al yo. El goce es aquello que escapa a la representación significante, es lo que hace agujero, y es justo por esto que se encuentra en el fundamento del sistema significante; constituye el campo de lo real como aquello que no puede ser significado y que atañe a la pulsión de muerte, la cual no cesa en el intento para satisfacerse -concepto de repetición-. El deseo, por su parte, es inconsciente y se constituye a partir de los significantes venidos del campo del Otro (orden simbólico), actuando como contraparte del goce en lo referido a la satisfacción pulsional y apuntando, más bien, hacia un horizonte para la satisfacción, puesto que depende siempre del deseo del Otro; el deseo, entonces, se efectúa por la vía fantasmática primordial. El fantasma es la forma como el yo construye una ficción que encubre la satisfacción de las pulsiones agresivas y sexuales -lo real-; se constituye en el entrecruzamiento de los registros imaginario y simbólico. 
pueden llegar a tener los procesos de acompañamiento psicológico basados en dispositivos de escucha dentro de un establecimiento penitenciario.

Los referentes teóricos revisados en torno al tema del delito, desde las investigaciones y escritos psicoanalíticos, permitieron definir las categorías principales: la posición subjetiva, el acto, las categorías clínicas del acto (pasaje al acto y acting $o u t)$. Otras categorías emergentes surgieron en el transcurso de la misma: asentimiento subjetivo, responsabilidad subjetiva, relación al Otro, sanción penal, cuya caracterización se presenta de manera sintética a continuación.

\section{Posición subjetiva}

Para definir esta categoría, se hace indispensable plantear la noción de sujeto desde una perspectiva estructural del lenguaje y la palabra. Lacan (2006) define al sujeto como lo que está hecho por el discurso e incluso atrapado en él, por lo que se encuentra en el lugar de la enunciación desde donde da cuenta de su relación con el mundo simbólico en el que habita. Estos elementos de la lingüística permiten al psicoanálisis explicar la relación que tiene un sujeto con el Otro como lugar simbólico de la palabra. En relación con lo anterior, la posición subjetiva se revela precisamente allí, en el punto del discurso donde emerge la relación singular del sujeto con el Otro.

En el caso del delito, la posición subjetiva enseña los elementos propios de la estructura del sujeto que pueden llevar a cometer y repetir dicho acto. Es importante indicar que, al definir el delito a partir de una lógica simbólica, se implica al sujeto de la enunciación; es decir, se desvelan las implicaciones singulares y la posición del sujeto frente a las consecuencias de su acto. Esto permite indicar, como dice Braunstein (1982:52-53), "las modalidades particulares de ese sujeto en la relación que tiene con la realidad exterior y en el manejo que hace de sus pulsiones". Apuntamos aquí que este manejo que hace de sus pulsiones remite a la posición que el sujeto asume frente a su goce, no frente a su conducta; la posición subjetiva, de esta manera, está en relación con la línea sincrónica de la historia que lo constituye como sujeto.

\section{Acto}

La cuestión del acto se toma desde una vertiente estructural en la cual este es leído. Así, al hablar del sujeto del inconsciente, se tiene en cuenta lo que es revelado a partir de ciertos fenómenos del lenguaje; por tanto, el acto es un fenómeno simbólico susceptible de ser interpretado en la vía del lenguaje, diferenciándose de la acción motriz, de la conducta. 
En la dimensión del acto inmediatamente surge (...) la inscripción en alguna parte, el correlato del significante, que en verdad no falta jamás en lo que constituye un acto: puedo acá caminar a lo largo y a lo ancho mientras les hablo; esto no constituye un acto, pero si un día, por franquear un cierto umbral yo me pongo fuera de la ley, ese día mi motricidad tendrá valor de acto. (Lacan, 1967: 4)

Lo que es captado en la vertiente simbólica del acto, específicamente en la enunciación, es lo que emerge en el discurso del sujeto como la verdad del inconsciente; por tal motivo, el análisis de un acto delictivo para el psicoanálisis se toma como un hecho vinculado a la estructura simbólica en la que está inmerso el sujeto en relación con su verdad; verdad íntima que le compete y que lo implica estrechamente con su acto.

La verdad de la que se trata aquí es definida por Lacan (2006) como algo que emerge en la palabra y que se dice más allá de lo enunciado, generando sorpresa para quien se implica en lo que ha dicho. Esto indica que la verdad, en todos los casos en que se escucha al sujeto, en la enunciación, aparece como sorpresiva; sorprende en la medida en que está vinculada con el deseo de eso que habla: "la verdad en juego en el psicoanálisis es lo que por medio del lenguaje (...), por la función de la palabra, toca un real" (Lacan, 2012: 67).

En resumen, el acto refiere a la lógica significante, a la lógica de la palabra y el lenguaje. Una dimensión meramente humana con la cual se ubica en el sujeto una posición en relación con su deseo y con su goce, siendo que, en esto último, se verifica algo de lo real que se impone al sujeto y que se manifiesta en su acto.

\section{Categorías clínicas del acto}

Dentro del acto se conciben dos categorías clínicas que están implicadas en la lógica de este. Una de ellas es el acting out, en el cual el sujeto pone "en escena" un acto con el que hace un llamado de interpretación al Otro. Al respecto, dice Gerez-Ambertín (2009:57): "se trata de un llamado al Otro simbólico cuando amenaza la angustia y flaquea la palabra”. Aquí, la autora indica que en este fenómeno psíquico se trata de un salir de la escena que se establece entre el sujeto y el Otro, es decir, se rompe con el lazo que implica la relación con la cultura y sus códigos particulares; no obstante, hay una re-inscripción significante, en tanto este movimiento subjetivo es un hecho del lenguaje a ser leído o interpretado. Este tipo de acto se caracteriza porque el sujeto puede dar cuenta de él en su reconstrucción y, asimismo, asumir sus consecuencias.

De otro lado, el pasaje al acto implica el paso a una realización de goce; a diferencia del acting out, “"no quiere' decir” (Soler, 2010: 42), sino que busca la vía de satisfacción en la cual el sujeto desaparece radicalmente de la escena que media la relación con el Otro. Esta categoría clínica del acto retrocede hacia lo real, pues no puede inscribirse 
en la cadena simbólica para ser leído o interpretado. Soler (2010:43) argumenta que "esa es la temporalidad misma de la pulsión como empuje incoercible".

\section{Relación al Otro}

Con el fin de definir esta categoría, es necesario decir primero unas palabras en relación con la noción del Otro, puesto que esta condensa una serie de significaciones que se desarrollan a lo largo de la teoría de Lacan (2007), quien la define como tesoro del significante y sede del código, siendo esta idea fundamental con relación a todas las demás significaciones que la van enriqueciendo $\mathrm{y}$, esencialmente, con aquella que, en esta investigación, se toma como pilar: el Otro del lenguaje como estructurador del sujeto y del discurso en el que vienen a lugar las dimensiones de la ley en sus vertientes psíquica y social (discurso jurídico).

Así, con este desarrollo temático, puede definirse la relación del sujeto con el Otro como el lazo con todas las formas de la ley que limitan, encuadran y hacen posible tanto la vida como la identidad del sujeto, y también como con esa forma de la ley (Superyó) que empuja al goce (Braunstein, 2006).

\section{Sanción penal}

Debe realizarse la diferenciación entre la sanción penal entendida desde el discurso jurídico y el discurso psicoanalítico. Para el primero, la sanción se refiere a la pena que un individuo recibe por una conducta punible, definida de manera inequívoca por la Ley Penal en su código (Congreso de Colombia, 200o), siempre y cuando haya sido declarado responsable de esta. La pena tiene como funciones la prevención general, la retribución justa, la prevención especial, la reinserción social y la protección del condenado. Desde el psicoanálisis, la sanción penal se contempla en el marco de la subjetividad, "en tanto existe una inequívoca relación entre el inconsciente del sujeto y la ley" (Sarrulle, 2006:33); o, dicho en otras palabras, cuenta con la inscripción del sujeto en otra ley, la psíquica, que actúa como reguladora y re-ordenadora del deseo y el goce. De este modo, la transgresión de esta ley supone la correspondencia culpa-castigo y, por ende, una respuesta subjetiva frente al delito, pero ya no tomando este como conducta, sino como acto.

En ambos casos, la ley marca un límite que el sujeto no debe franquear y establece la distinción entre lo permitido y lo prohibido, porque de eso depende el sostenimiento del lazo social. En el caso de la ley psíquica, el psicoanálisis reconoce en el sujeto una deuda simbólica que deja en este su inscripción en la ley; además, indica que se 
produce en él una culpa por "una tentación siempre renovada a franquear los bordes que demarcan lo prohibido pues, desde el momento en que se señalan los límites, se abre el espacio a una transgresión siempre posible" (Gerez-Ambertín, 2004:19). Por tanto, esta dimensión de la ley psíquica es imprescindible para subjetivar la pena, debido a que, si no existiese esta subjetivación, la aplicación del castigo por parte de la ley jurídica posibilitaría una posición especular entre la ley, el castigo y el reo.

\section{Responsabilidad subjetiva}

La orientación que da el psicoanálisis a la noción de responsabilidad va vinculada al deseo inconsciente, el cual se encuentra estrechamente enlazado con la ley fundante de la cultura humana y no con la voluntad ni el capricho del individuo, siendo, en esta medida, que el deseo y la ley están íntimamente ligados (Carol, 1999).

La responsabilidad, por su parte, está ligada al concepto de culpa y podemos encontrar la culpa en varios registros, tal y como lo muestra Gerez-Ambertín (2013). En primer lugar, la culpa consciente, cuya expresión se encuentra vinculada a un sentimiento, el de culpa, donde el solo hecho de que este sentimiento sea percibido por el Yo da cuenta de las intersecciones entre los registros imaginario y simbólico; aquí la preeminencia la da el significante. Además, existe la culpa inconsciente, relacionada con la castración, en la medida en que se hace una "invocación a la falta del Otro" y que se encuentra en la intersección de los registros simbólico y real. Por último, en la culpa muda, el significante no tiene cabida y está en relación con un Superyó voraz y gozador; esta culpa se encuentra en la intersección entre lo imaginario y lo real.

En relación con el acto delictivo, la responsabilidad de un condenado se devela en su testimonio, en el discurso que lo determina a partir de su relación al Otro y en el deseo que se inscribe a partir de esta relación, así como en el goce que emerge como plus en la satisfacción pulsional parcial que guía el acto. Un sujeto es entonces responsable en la medida que desvele, en el discurso, su implicación con lo que lo causa como sujeto deseante y frente a lo que hace marca en su cuerpo como sustancia gozante, lo que opera de empuje a pesar y en contra de la voluntad consciente, y que no cesa en su repetición.

\section{Asentimiento subjetivo}

Es importante anudar esta categoría con la de responsabilidad subjetiva, puesto que el asentimiento subjetivo es condición necesaria para ubicar la posición responsable 
de un sujeto frente a su acto, indicándose aquí un paso lógico y necesario, tanto para la significación del castigo como del acto mismo (Carol, 1999). Dicho paso se encuentra dentro de una secuencia en la que puede verificarse la posición subjetiva de quien delinque. Gerez-Ambertín (2006) indica que, en el asentimiento subjetivo, el sujeto se encuentra en una relación cuatripartita: acto criminal-culpa-responsabilidad-significación de la sanción penal; dicha cadena lógica permite pensar en una posición singular del sujeto ligada al discurso del Otro como ley.

En este punto, es importante tener en cuenta lo que dice Lacan (2010) acerca del asentimiento subjetivo, con relación a los elementos conceptuales antes mencionados.

Toda sociedad, en fin, manifiesta la relación entre el crimen y la ley a través de castigos cuya realización, sea [sic] cuales fueren sus modos, exige un asentimiento subjetivo. Que el criminal se vuelva por sí solo el ejecutor de la punición, convertida por la ley en el precio del crimen. (130)

De acuerdo con esta referencia, en el asentimiento subjetivo se halla la posibilidad de encontrar un lugar para un sujeto que responde de su acto criminal a partir de una significación singular de la pena y una asunción de eso que viene del Otro como sanción, teniendo a su vez ese acto una estructura de testimonio formulado en la lógica significante del inconsciente, que le da el sentido particular a su crimen.

\section{Método}

La presente investigación es de carácter cualitativo. En ella se realizó una indagación, a través de entrevistas de localización subjetiva, a seis hombres adultos condenados por delitos de homicidio y abuso sexual con menores de 14 años, con pena privativa de la libertad en el Establecimiento Penitenciario de Mediana Seguridad y Carcelario de Pereira. No se tuvo en cuenta a personas sindicadas que estuvieran bajo medida de aseguramiento, porque, aun habiendo estado privadas de la libertad, no se encontraba desvirtuado el principio de inocencia mediante un juicio público; por consiguiente, no se les había responsabilizado judicialmente por el acto delictivo. Tampoco se contó con personas con trastornos psiquiátricos en estado de descompensación que no estuvieran recibiendo medicamentos ni aquellos que presentaran déficits cognitivos diagnosticados.

La entrevista de localización subjetiva surgió de la experiencia clínica del psicoanálisis, específicamente del marco previo a la entrada en el mismo: las entrevistas preliminares. Estas tienen como objetivo realizar una escucha que permita indagar y extraer, caso por caso, los efectos que una vivencia determinada causa a nivel psí- 
quico. De este modo, dicha entrevista fue considerada la fuente de información por excelencia y se tomó como fuente primaria; con ella, lo que se trató de establecer, como plantea Miller (como se citó en Gallo; Ramírez, 2012: 115), es "qué es lo dicho para el sujeto, si retroactivamente niega o confirma la afirmación, si lo dicho es de él o es una 'cita del discurso del Otro'”. En el uso de esta entrevista, el investigador debe "cuidar de no reducir el sujeto a sus dichos y tener en cuenta la emergencia del decir, la cual se produce en la medida en que se cuestione la posición de dicho sujeto con respecto a lo que enuncia" (Gallo; Ramírez, 2012: 113); además, en esta distinción puede entenderse la diferencia entre la investigación social cualitativa y la investigación psicoanalítica.

A través de este tipo de herramienta metodológica se buscó, en un primer momento, pasar del nivel de la observación al de la escucha o, en palabras de Miller (2006), de la dimensión del hecho a la de lo dicho o lo enunciado. Y, en un segundo momento, pasar de los dichos al decir; esto es, ingresar en el nivel de la enunciación, ya que lo inconsciente no aparece en el enunciado, sino en la enunciación. Así las cosas, lo que interesa extraer de estas fuentes primarias no es propiamente lo inconsciente, "sino el lugar donde en rigor se intenta leer lo que hace marca significante" (Gallo; Ramírez, 2012: 114), porque es la enunciación la que indica la posición del sujeto frente a su enunciado.

Para realizar la entrevista de localización subjetiva, previo consentimiento informado y firmado por los participantes, los investigadores se apoyaron, inicialmente, en preguntas abiertas, basadas en las categorías temáticas. Estas se elaboraron a partir de la pregunta de investigación, lo cual facilitó que el encuentro se condujera de modo similar a una entrevista preliminar, diferenciándose aún más el dispositivo de la investigación respecto del clínico. Lo dicho por los entrevistados fue grabado y luego se inició el proceso de transcripción, teniendo en cuenta que se trataba de una estructura de discurso y, por lo tanto, de voz, de testimonio y de texto. De este modo, la transcripción se realizó teniendo a la escucha como herramienta primordial del proceso, para poder captar los elementos significativos como las paradojas, falacias, negaciones, contradicciones, titubeos, lapsus y ambigüedades, que son las que arrojarían una radiografía clara de la división del sujeto, en cada una de ellas.

Una vez transcritas las entrevistas, se llevó a cabo un trabajo de desciframiento que recayó sobre cada uno de los testimonios tratados como textos que narraban una historia, y en los que se seguía una argumentación por parte del entrevistado. Como discurso, ese decir se somete a una lógica de ordenamiento en la que, no obstante, pueden localizarse momentos de ruptura, discontinuidades, momentos de repetición significante, sincronías que, al conectarse, respaldan aquello que insiste en el discurso de ese sujeto singular y que permite ir desvelando algo de su 
posición frente al acto delictivo, como asuntos relacionados con la identificación, el goce, el deseo, el fantasma, la posición frente al Otro y la relación a la castración, fundamentalmente.

En las entrevistas tomadas como casos, el análisis supuso una construcción que partió de los significantes proferidos por el entrevistado, para formalizar algo de la posición subjetiva que se develó en el acto criminal. Esto implicó pasar de lo que fue dicho en términos de la expresión cotidiana, a la construcción-haciendo uso de una rejilla- de un ordenamiento de los elementos en relación con unos puntos nodales: nociones como posición subjetiva, culpa (remordimiento, culpa inconsciente y culpa muda), responsabilidad subjetiva, relación al Otro, y las categorías clínicas del acto (pasaje al acto y acting out). A partir de esto, se volvió sobre estos elementos para elaborar una construcción lógica acerca de lo que giraba alrededor de las categorías propuestas, permitiendo, de ese modo, el desciframiento del aspecto subjetivo que interesaba indagar: la emergencia en el discurso de la posición subjetiva con relación a las categorías clínicas del acto.

Finalmente, fue posible reconocer la particularidad del acto en cada caso; es decir, ubicar en el delito la emergencia de un pasaje al acto o de un acting out, pero también realizar un análisis situando elementos comunes, sin perder de vista que se trataba de la particularidad de cada uno de los condenados.

\section{Resultados}

Los resultados de la investigación son producto del análisis de las entrevistas realizadas: tres casos concernientes al delito de homicidio y tres, al de abuso sexual con menores de 14 años; sin embargo, para efectos de este artículo, se elige un caso de homicidio en el que se ejemplifican las categorías de análisis. La elección de un solo caso está basada en el interés de comprender la estructura de discurso singular, en la cual se juega el lugar del sujeto en tanto histórico; no se trata entonces de buscar validez externa, sino la lógica del fenómeno en su particularidad, lo que no puede conseguirse por la vía inversa, es decir, desde el conocimiento de la generalidad hacia su aplicación en los procesos psíquicos. El abordaje de la subjetividad implica tomar, caso por caso, los aspectos singulares que pueden tener efecto en lo social, sin buscar una generalización de la posición subjetiva. De esta manera, el estudio del delito como acto permite entender que, dentro de un fenómeno como este, se pueden hallar múltiples sentidos.

Así las cosas, lo que interesa al psicoanálisis, en este punto, es el significante que representa a un sujeto en su historia, con relación a su acto. Este criterio se encontró 
en los seis casos analizados y puede verse claramente en el elegido para el presente artículo, caso que se nombró por medio del significante con el que el sujeto se identificaba: Papito. De este modo, se dice algo de su particular posición y se preserva, al mismo tiempo, la identidad del entrevistado.

\section{Caso Papito: \\ la posición subjetiva y las categorías del acto en el delito de homicidio}

Papito se encuentra condenado por dos delitos: concierto para delinquir y homicidio. Se trata de un hombre que proviene de una familia muy pobre; no conoció a su padre y la madre lo abandonó junto a sus hermanos, estando estos pequeños; tiene una compañera ("No soy casao' pero tengo un hogar" [Papito, comunicación personal, 01.08.2016]), y teniendo hijos se hace al lugar del padre. Papito es la manera como se le conoce desde la adolescencia, y respecto a este sobrenombre hallamos que él encuentra la manera de hacerse llamar de este modo por personas ajenas, mientras que la familia de origen, su esposa e hijos siempre le dicen Papito.

Al inicio de la entrevista, Papito (comunicación personal, 01.08.2016) se precipitó a decir algo acerca del delito cometido: "Hay errores que se cometen... y los errores a veces se pagan caro también". Al describir el error se justificaba: "pues, en esos, en ese tiempo yo estaba, pues, sin trabajo, teniendo dos hijos (...) entonces no tenía yo, pues, forma de, de tener un sustento, para poder sostenerlos un diciembre, sin tener, sin tener, ¿cómo le dijera?, poder darle algo a ellos, entonces me salió un trabajo a mí de que había que, suceder de, de asesinar a una persona (...)". Y, para señalar el nudo que complicó en ese momento su existencia, dijo: "Hay momentos que se cierran muy duros...".

La posición subjetiva de Papito (comunicación personal, 01.08.2016) se capta en un apartado de la entrevista donde es posible aislar la Verneinung freudiana: "No era para mí, yo no haberme metido en eso". Así, mientras el yo se engaña creyendo haber dicho que no era para él haberse metido en ese problema, el sujeto muestra, mediante la negación, que es su elección haber llevado a cabo el acto. Esta división subjetiva permite, a la vez, apreciar el fenómeno psíquico de la responsabilidad subjetiva, 
noción psicoanalítica que se revela en el fondo de la estructura de los enunciados con los cuales el entrevistado procura darle un sentido consciente a su relato y una justificación objetiva a su acto; sin embargo, en el análisis estructural que se hace desde el psicoanálisis, se puntualiza el decir que testimonia lo que realmente es la motivación de un sujeto para llevar a cabo un acto, en este caso, participar de un homicidio.

La responsabilidad subjetiva se liga en este sujeto a un sentimiento de culpa relacionado con los registros imaginario y simbólico, que pueden apreciarse en su discurso cuando se refiere al error cometido. El error se justifica por no tener trabajo y tener necesidades económicas, especialmente al ser época de Navidad. El yo rechaza lo que viene del deseo inconsciente, pues sabe que le han propuesto realizar un asesinato y dice: "Me tocó recurrir a lo que, a lo que pue... pues no quería, pero viendo a mi familia" (Papito, comunicación personal, 01.08.2016).

La culpa inconsciente puede apreciarse en ese lapsus que delata la verdadera posición subjetiva frente al acto y que ya hemos mencionado antes: "No era para mí, yo no haberme metido en eso" (Papito, comunicación personal, 01.08.2016). Es notorio que en la enunciación el sujeto evidencia el deseo inconsciente que se encuentra implicado. Lo mismo sucede frente a una pregunta que se relaciona con otros comportamientos delictivos, como es el robo: "Yo no soy una persona que no me gusta coger lo ajeno" (Papito, comunicación personal, 01.08.2016). Y no aparece ligado a otros enunciados de la entrevista que no impliquen actos delictivos.

Este sujeto de la enunciación aparece también en otro apartado de la entrevista ligado al deseo inconsciente de tomar objetos que no son de su pertenencia, y lo hace al referirse a aquello que le impide robar:

Me impide, por ejemplo de yo ir y coger lo ajeno, de perder la confianza en el patrón porque pa' eso lo mandan a uno, pss si a uno lo mandan a hacer un trabajo en una casa 'onde sabe que, por ejemplo, que yo he estado en casas ricas pintando paredes, instalando cielo rasos y usted ve por ejemplo un teléfono, una cadena y usted llevársela sabiendo que es el único que dentró, entonces van a llegar quejas 'onde el patrón: “iCómo le parece que se me perdió una cadena!”, entonces ya el patrón va quedar en dudas con uno. (Papito, comunicación personal, 01.08.2016) 
El Otro se revela como límite, lo que muestra que reconoce el Otro de la ley. De hecho, en este párrafo, pareciera decir que no robaría para no perder la confianza del patrón, lo cual estaría del lado del sentimiento consciente de culpa (remordimiento); no obstante, la culpa inconsciente se revela en el hecho de haber visto los objetos que podría eventualmente robar: un teléfono, una cadena. Lo que enuncia reseña la presencia del deseo en tanto tentación que se oculta a la mirada del Otro, y esto es lo que señala la construcción fantasmática en este sujeto.

La ubicación de la culpa muda, en este caso, da cuenta del anudamiento entre el registro real y el imaginario, tal como se revela en el decir del sujeto; así, justo en el momento cuando dio su asentimiento para la comisión del asesinato. Expone que le dio un arrebato: "Un arrebato. Del arrebato de, de... [silencio] de ser otra persona, como que uno cambia" (Papito, comunicación personal, 01.08.2016). Este apartado muestra el paso de un sujeto que puede, eventualmente, inhibirse e incluso echarse para atrás frente a este hecho, a uno que es empujado a gozar, fracasando en ese momento la operación de lo simbólico en el lazo con el Otro. Al interrogarlo por ese "ser otra persona", expresó algo que tiene todas las coordenadas del imperativo superyoico, algo que lo exhortó: "¡Vamos! ¡Vamos! ¡Hágale! Y como que no piensa uno, no piensa uno en nada. Vamos, hágale" (Papito, comunicación personal, 01.08.2016). Un plus de gozar desconectado de lo simbólico, tan estático como real.

No obstante, se encuentra también otra vertiente del goce que se significantiza a modo de una "escaramucia" en el cuerpo. Es así como, para Papito, el goce es referido como un significante que evoca en relación tanto con el encuentro sexual como con el acto criminal. Respecto a ambos, intenta poner en palabras eso que invade el cuerpo y en su relato se hace evidente que, en el caso de lo sexual, se encamina a la construcción de fantasías; mientras que, en el caso del acto criminal, aparece como una rememoración de las detonaciones del arma homicida. De este modo, Papito responde con una "escaramucia" a eso real que invade su cuerpo.

Aunque es claro que en este sujeto se encuentran todas las dimensiones de la culpa, también es posible, mediante su decir, el hallazgo de la lógica subjetiva del caso, donde hay, de todas maneras -a pesar de este empuje al goce-, algo que le permite una invocación al Otro y por ende, 
reintroducirse en el registro de lo simbólico, esto que anuda toda la escena y que se ubica en su discurso como una necesidad de dar a sus hijos el alimento, el vestido, la cena de Navidad, los regalos -cosas que él mismo dice no haber tenido nunca-, un papito que cumpliera con proteger, cuidar y dar a sus hijos una Navidad.

$\mathrm{Al}$ tener en cuenta lo anteriormente mencionado, con relación a las categorías del acto, hallamos el pasaje al acto anudado a los registros imaginario y real, punto nodal de la coacción de repetición. Frente a esto, se encuentra que él no es el mismo antes y después de dar el consentimiento para cometer el homicidio, pues al hacerlo ya no puede volver atrás. Más adelante, respecto al homicidio cometido, señaló: "Ya no soy el mismo, (...) ya no soy la misma persona, primero era (...) ¿Cómo le explicara? [silencio], si eso hace, hace que las cosas cambien de uno" (Papito, comunicación personal, 01.08.2016). Se observa la dificultad de pasar eso por la palabra.

En el discurso de Papito puede encontrarse, también, la coordenada de su acto como acting out, puesto que este sujeto se encuentra en la imposibilidad de solventar las necesidades de la familia y acontece allí un "cerrársele el mundo", que hace serie con todos los cerrársele el mundo que aparecen en su decir cuando se encuentra en la posición de percatarse de la falta en el Otro. Esta lógica devela una escenificación que gira en la relación de él con el Otro, de lo que le falta y de lo que invoca del Otro (familia, un padre, sustento familiar, Navidad), para lo cual se hace a un significante que simboliza el lugar de la falta: significante Papito, como él se hace llamar.

En conclusión, la relación de este sujeto al Otro se encuentra mediada por la ley, en tanto esta opera entre la fantasía y el pasaje al acto, inhibiendo este último; por ello es importante tener en cuenta que este sujeto no fue quien asesinó a la víctima, sino que participó como cómplice.

La pena impuesta por el sistema judicial aparece, para este sentenciado, como la justa consecuencia de su acto ("Como se lo merece uno (...) para mí, para mí es justo, no es, no digamos que es mucho, ni más ni menos, eso y está bien, yo acepto mi condena" [Papito, comunicación personal, 01.08.2016]). Por el análisis, es claro que en este sujeto se plantea la seriación crimen-culpa-responsabilidad-sanción penal, lo cual 
indica que él se relaciona con cada uno de los elementos que articulan la serie y, por lo tanto, puede hablarse, en su caso, de una implicación subjetiva plena, lo que permite concluir que, para él, la pena consigue inscribir su falta en el orden de la ley-ley psíquica y ley penal-, haciendo de este sujeto un posible beneficiario de un dispositivo psicoterapéutico de escucha y resocialización.

\section{Conclusiones}

La trama lógica que se vincula con el aspecto de la subjetividad, el acto delictivo y las categorías clínicas del acto se enmarca dentro de cinco puntos interconectados: el significante, el goce, el cuerpo, el fantasma y las categorías clínicas del acto.

Es preciso argumentar que el significante es el recurso con el cual un sujeto se da un lugar particular en el mundo, en este caso, a partir del análisis del acto criminal homicida. También es posible ubicarlo como el elemento que da a conocer la particularidad en el acto criminal. De acuerdo con esta lógica, se comprende, en el caso de Papito, que la función significante es lo que ha fundamentado la posición subjetiva; asimismo, es lo que ha posibilitado seguir la huella del camino que se traza partiendo de una marca simbólica, y operando desde su singularidad en un discurso determinado, como lo es el social. Este significante (Papito) se entrelaza con la cultura y representa una parte abyecta del sujeto; del mismo modo, la palabra "escaramucia" encarna el intento del sujeto por hacer pasar por la palabra ese real insoportable que invade al cuerpo como sustancia gozante.

En este caso, lo fantasmático es revelado en la enunciación, siendo posible ubicar los elementos que lo componen: el deseo, el objeto, la división del sujeto y el goce, lo que da cuenta del marco de referencia desde donde el sujeto ve y vive su existencia. De este modo, puede indicarse la manera como Papito responde de su ser en la vía del deseo: el papito de la familia, un papito proveedor. Igualmente, se encuentra el circuito de la pulsión y los objetos orales, objetos de la demanda dirigida al Otro, lo que el sujeto pide al Otro que, en este caso, es comida, protección, amor, cuidado y trabajo, para sí mismo y para los suyos. Esta demanda entra en un cortocircuito por la contingencia de quedar sin trabajo. El Otro se revela de nuevo en falta, dejándolo desprovisto de recursos, sin sostén, y es ahí cuando acontece para el sujeto un "cerrársele el mundo" que lo deja a expensas del goce. 
Los objetos escópicos emergen como aquello deseable en el Otro, objetos que pueden colmar la falta y generan la tentación de ser tomados (robados al Otro), tentación que indica la división del sujeto dentro de la escena fantasmática; así, en lo descrito más arriba, esto se da a ver en el decir del sujeto entrevistado. En la lógica del caso se van anudando el pasaje al acto y el acting out, presentándose como momentos diferenciados en la confrontación con la falta en el Otro, puesto que el acto se revela como la respuesta a eso insoportable de la castración.

Finalmente, es importante indicar la relación estrecha que, dentro de una lógica moebiana, se ha obtenido del análisis de los componentes posición subjetiva y categorías del acto, pues ambas dimensiones se entrecruzan en la misma vía del acto, pero en puntos diferentes de la lógica discursiva del caso. En cuanto a la categoría del acting out, el entrecruzamiento se da en la medida en que hay mostración fantasmática del goce, así como un movimiento de salida y retorno del sujeto a la escena mediante una lógica dialéctica significante, lo que posibilita ubicar, en la línea del lenguaje, el punto cuando el sujeto se excluye de la escena, posibilitando, a su vez, la reincorporación a la escena por medio de la reconstrucción significante del hecho, con lo cual se da el reingreso a la estructura del discurso.

Por otro lado, la relación posición subjetiva-pasaje al acto se muestra en la relación con el deseo y la división que este conlleva, haciendo que, en un momento dado, el sujeto solo pueda responder borrándose de la escena, marcando un antes y un después, sin la posibilidad de rectificar esa posición, la cual se coagula en la decisión de cometer un acto criminal: el concierto para delinquir y el homicidio.

A partir de las consideraciones anteriores puede verse, de manera clara, cómo la subjetividad juega un papel fundamental en el acto criminal, lo cual permite mostrar que no es lo mismo pensar el delito como conducta que pensarlo como acto, con todo lo que esto implica, porque, al concebirlo como un hecho de lenguaje, se presenta como discurso, como voz y como texto que puede ser descifrado, pudiendo dar cuenta de la posición subjetiva de quien delinque, pudiendo señalar la responsabilidad que atañe al sujeto respecto de su acto.

La responsabilidad del sujeto tiene que ver con el deseo inconsciente, sin importar cuál sea la estructura subjetiva ahí implicada. Tampoco importa que el acto delictivo sea conforme a la ley jurídicamente establecida, sino que, más bien, se refiere a una ley que juzga al sujeto en relación con la renuncia a su deseo inconsciente.

De este modo, el discurso del derecho se sitúa alrededor de la ley como pacto que debe respetarse bajo la suposición de que esta es justa, en cuanto vela por el bienestar de los individuos y, bajo este precepto, interroga al psicoanálisis para que le brinde un conocimiento acerca del acto delictivo en varias vertientes: sobre la determinación causal del delito, la determinación respecto de si un individuo es o 
no el autor de un acto criminal, o de la definición acerca de si el individuo puede ser juzgado por sus características clínico-patológicas.

Pero el psicoanálisis no responde desde ese lugar, porque está por fuera de la razón práctica que le demanda el discurso jurídico, ya que tal razón lo conduciría a establecer una diferencia entre lo que está bien y lo que está mal, entre lo sano y lo enfermo, entre lo funcional y lo disfuncional, entre lo cognitivo y lo psíquico, sintonizándose con las concepciones de la ley positiva. El psicoanálisis no se pone del lado de la convención, solo participa en cuanto a la subjetivación del acto criminal, y de la pena impuesta por la sociedad y la ley a través de la relación analítica.

No obstante, al poder señalar la relación del sujeto con la ley psíquica, se advierte al discurso jurídico respecto de la necesidad de tener en cuenta la vertiente de la subjetividad, para lograr, en los condenados, la subjetivación de la sanción penal, y que esta no resulte inútil en aquellos casos donde es posible subjetivarse, teniendo en cuenta que aquello que es silenciado encuentra siempre las vías de hacerse escuchar, y eso implica, por ejemplo, las reincidencias en los actos criminales.

\section{Referencias}

Braunstein, Néstor Alberto (1982). La psicología y la teoría psicoanalítica. En Psicología, ideología y ciencia (pp.47-61), coordinado por Amelia Rivaud; Néstor Alberto Braunstein. México: Siglo XXI.

Braunstein, Néstor Alberto (2006). El goce, un concepto lacaniano (2. ${ }^{\mathrm{a}} \mathrm{ed}$.). Buenos Aires: Siglo XXI.

Carol, Alfredo Orlando (1999). La responsabilidad y sus consecuencias. En Culpa, responsabilidady castigo en el discurso jurídico y psicoanalítico (Vol. I) (pp. 55-62), compilado por Marta Gerez-Ambertín. Tucumán: Universidad Nacional de Tucumán.

Congreso de Colombia (2000). Ley 599 de 200o. Por la cual se expide el Código Penal. Recuperado de http://www.secretariasenado.gov.co/senado/basedoc/ley_0599_20oo.html

Gallo, Héctor; Ramírez, Mario Elkin (2012). El psicoanálisis y la investigación en la universidad. Buenos Aires: Grama.

Gerez-Ambertín, Marta (2004). La sanción penal: entre el “acto" y el "sujeto del acto". En Culpa, responsabilidad y castigo en el discurso jurídico y psicoanalítico (Vol. 2) (pp. 17-36). Buenos Aires: Letra Viva.

Gerez-Ambertín, Marta (2006). Ley, prohibición y culpabilidad. En Culpa, responsabilidady castigo en el discurso jurídico y psicoanalítico (Vol. 1) (pp.37-56). Buenos Aires: Letra Viva. 
Gerez-Ambertín, Marta (2009). Vicisitudes del acto criminal: acting out y pasaje al acto. En Culpa, responsabilidad y castigo en el discurso jurídico y psicoanalítico (Vol. 3) (pp. 49-76). Buenos Aires: Letra Viva.

Gerez-Ambertín, Marta (2013). Las voces del Superyó en la clínica psicoanalítica y en el malestar en la cultura (2.a ed.). Buenos Aires: Letra Viva.

Lacan, Jacques (1967). Clase 1 del 15 de noviembre de 1967. En El seminario XV: el acto analítico. (pp. 1-13) (Ricardo Rodríguez Ponte, trad.). No editado. Argentina: Escuela Freudiana de Buenos Aires.

Lacan, Jacques (2006). Mi enseñanza. Paidós: Buenos Aires.

Lacan, Jacques (2007). La forclusión del Nombre del Padre. En El seminario, Libro 5: las formaciones del inconsciente (pp. 147-164). Buenos Aires: Paidós.

Lacan, Jacques (2008). Producción de los cuatro discursos. En El seminario, Libro 17: el reverso del psicoanálisis (pp. 9-28). Buenos Aires: Paidós.

Lacan, Jacques (2010). Introducción teórica a las funciones del psicoanálisis en criminología. En Escritos I (2. ${ }^{\mathrm{a}}$ ed.) (pp. 129-150). Buenos Aires: Siglo XXI.

Lacan, Jacques (2012). Saber, ignorancia, verdad y goce. En Hablo a las paredes (pp. 11-46). Buenos Aires: Paidós.

Miller, Jacques Allain (2006). Introducción al método psicoanalítico. Buenos Aires: Paidós.

Sarrulle, Oscar (2006). El sentido de la pena en el derecho argentino. En Culpa, responsabilidad y castigo en el discurso jurídico y psicoanalítico (Vol.1) (pp.31-36), compilado por Marta Gerez-Ambertín. Buenos Aires: Letra Viva.

Soler, Colette (2010). El sujeto del acto. En Acto, pasaje al acto y acting out en psicoanálisis (pp. 35-43), compilado por Gloria Gómez. Bogotá: Temas Cruciales.

Soler, Colette (2015). ¿A qué se le llama perversión? Medellín: Asociación Foros del Campo Lacaniano de Medellín. 